\title{
Metodologia de Trabalho de Campo com Licenciandos em Ciências Biológicas para o Ensino Inclusivo de Cegos
}

\author{
Field Work Methodology with Biological Sciences Graduates for the \\ Inclusive Education of Blind people.
}

\section{Luis Otávio Pimentel Santos ${ }^{1}$, Ruth Maria Mariani ${ }^{2}$, Cláudia M. Lara Mello Coutinho ${ }^{3}$}

1 Mestre em Diversidade e Inclusão, UFF, Niterói, Estado do Rio de Janeiro, Brasil - E-mai otaviopimentel@bol.com.br ,/ORCID: https://orcid.org/0000-0003-0827-7680.

2 Doutora em Ciências e Biotecnologia, atuando no CMPDI/UFF, Niteroi, Estado do Rio de Janeiro, Brasil - E-mail, ruthmariani@yahoo.com.br /ORCID: https://orcid.org/0000-0003-2224-9643

3 Pós-doutorado no Instituto Pasteur de Paris, Atuando no CMPDI/UFF, Niteroi, Estado do Rio de Janeiro, Brasil- E-mail claudialaramelocoutinho@gmail.com /ORCID: https://orcid.org/0000-0002-5423-3032

\section{Recebido em Agosto/2019. Publicado em Agosto/2020}

Palavras-chave: Inclusão, Deficiência Visual, Vídeo, Formação Docente.

\section{Keywords:}

Inclusion, Visual Impairment, Video, Teacher Training.
RESUMO: O presente trabalho foi realizado durante o processo de formação acadêmica de licenciandos, que foram expostos a situações que permitem discutir e aplicar estratégias voltadas para a educação inclusiva. Assim, desenvolvemos, aplicamos e avaliamos metodologia de ensino inclusivo que buscou integrar licenciandos em Ciências Biológicas e colaboradores cegos durante trabalho de campo para estudo e reconhecimento de organismos marinhos coletados em uma praia urbana. Os licenciandos de olhos fechados, manipularam e exploraram as características dos organismos marinhos previamente coletados, como também os colaboradores cegos e descrevendo-os para os licenciandos que novamente de olhos fechados confeccionaram um segundo modelo com base nas características descritas pelos cegos, para efeitos de comparação. Foram aplicados dois questionários para avaliar percepções de licenciandos relativas a práticas inclusivas, relativas à metodologia desenvolvida de ensino inclusivo, em particular, antes e após o trabalho de campo. Os resultados nos permitiram concluir que o simples fato de aproximar videntes e cegos ao ar livre, em condições lúdicas de aprendizagem, possibilitou mudanças positivas de percepções dos licenciandos sobre habilidades e potencialidades dos cegos. Concluímos, que a metodologia desenvolvida tem potencial como prática alternativa de ensino que privilegia o conjunto dos sentidos e a troca de experiências para a promoção da inclusão de pessoas cegas.

ABSTRACT: Graduates were exposed to situations that allow discussing and applying strategies focused on inclusive education. Thus, we developed, applied and evaluated inclusive teaching methodology that sought to integrate graduates in biological sciences and blind collaborators during field work to study marine organisms collected on an urban beach. The blind-eyed licensees manipulated previously collected marine organisms as well as the blind collaborators and describing them to the graduates who again with closed eyes made a second model based on the characteristics described by the blind. Two questionnaires evaluated the perceptions of graduates about inclusive education before and after the field work. The results allowed us to conclude that the simple fact of approaching seers and blinds in the open air, under playful learning conditions, allowed for positive changes in the perceptions of the graduates about the abilities of the blind. We also conclude that our methodology has potential as an alternative teaching practice that privileges the set of senses and the exchange of experiences to promote the inclusion of blind 
people.

\section{INTRODUÇÃO}

A sociedade brasileira enfrenta um momento ambíguo na história. Discursos convocam para aceitação da diversidade, mas será que estamos preparados para, mais do que aceitar, incluir pessoas com deficiências e com necessidades especiais com igualdade de direitos?

Nas escolas, a falta de preparo dos professores é um dos obstáculos mais evidente para inclusão efetiva de crianças com deficiência na rede de ensino regular (BUENO, 1999; FREITAS, 2006). Alarcão (1996) e Oliveira (2002) reportam que uma atitude bastante comum entre os professores iniciantes é atribuir aos seus cursos de formação a responsabilidade por não possuírem conhecimentos práticos acerca da realidade da inclusão nas escolas.

Segundo Ferreira (2006), a aula inclusiva visa responder à diversidade de estilos de aprendizagem nos espaços formais de educação; então, qualquer ação de desenvolvimento e aperfeiçoamento de práticas de ensino e aprendizagem para a inclusão deve ajudar os professores a refletirem sobre a necessidade de seus alunos e o planejamento de atividades capazes de atender particularidades dos indivíduos e do grupo.

Trabalho de campo é considerado um importante aliado para o ensino de ciências, não só porque favorece a motivação dos alunos, como também se constitui uma estratégia pedagógica, capaz de ampliar nos alunos a visão de homem, de natureza e de ambiente (JACOBUCCI, 2008). Podemos inferir que o trabalho de campo possa trazer benefícios adicionais para o ensino inclusivo.

Este trabalho parte do princípio de que é muito importante que, durante o processo de formação acadêmica, licenciandos sejam expostos a situações que permitam discutir e aplicar estratégias voltadas para a educação inclusiva. Neste sentido, buscamos desenvolver, aplicar e avaliar metodologia com potencial para contribuir com a formação de professores visando à promoção da inclusão de alunos com deficiência, e, no caso específico, utilizando trabalho de campo que incluiu licenciandos e alunos com deficiência visual.

Ações inclusivas no ensino têm por objetivo a garantia do ingresso, regresso, permanência e sucesso das pessoas em situação de desigualdades, discriminação e ou vulnerabilidade social. Thomas, Walker \& Webb (1998) definem que uma escola inclusiva deve apresentar as seguintes qualidades: refletir a comunidade como um todo, com membros abertos, positivos e diversificados; não selecionar, não excluir e não rejeitar pessoas; não apresentar barreiras; ser acessível a todos, tanto em infraestrutura quanto em ferramentas 
educacionais (currículo, estratégias pedagógicas, metodologias de ensino e de comunicação, entre outras); trabalhar de forma integradora e não competitiva; promover a democracia e a equidade.

Segundo Freitas (2006), é muito comum que propostas feitas para a educação inclusiva sejam perdidas antes mesmo de serem implementadas na prática e, com isso, mudanças necessárias acabam no plano de realizações utópicas. Freitas entende que a formação de professores é base de todo processo possível para implantações efetivas e concretas de políticas voltadas para a educação inclusiva. Este autor alerta para o risco de que, durante a formação acadêmica, licenciandos terminem por fortalecer estereótipos sobre o que se considera um "aluno padrão", o que não lhes permitiria antecipar os desafios da diversidade que encontrarão na sala de aula real.

Segundo Masini (2007), o vidente estabelece a comunicação com o mundo desde o seu nascimento, em grande parte, estimulado pela visão de tudo que o rodeia. A visão é um sistema sensorial facilitador da percepção e interação com outros sistemas, possibilitando a identificação de contornos, cores, tamanhos e formas de objetos, podendo associar tais características a cheiros, sons e até comportamentos. Sem a visão, que é um sentido dominante, o indivíduo passa a se relacionar com o ambiente através de outros sentidos do corpo, os quais se tornam fontes de experiências e vivências que permitem significação do mundo ao seu redor. Neste sentido, torna-se fundamental pensar com cuidado e especificidade a educação para indivíduos que perderam a visão.

Layton \& Lock (2001) enfatizam que o indivíduo deficiente visual (DV), quando recebe intervenção apropriada, apresenta desenvoltura acadêmica condicionada somente às suas habilidades cognitivas inatas e adquiridas, e não relacionadas ao comprometimento de sua visão. Do ponto de vista pedagógico, o aluno DV ou com baixa visão deve ter experiências que preferencialmente sejam realizadas pelo toque e, ou pela voz.

A orientação do professor para a utilização dos recursos didáticos adaptados é fundamental para aumentar o interesse do aluno DV em relação aos conceitos científicos, bem como diminuir o desinteresse pelas aulas de ciências. Segundo Lederman \& Klatzky (1987), a modalidade tátil é extremamente confiável, pois inclui a percepção e a interação por meio da exploração sensorial do ambiente. É importante que as informações adquiridas através do tato sejam sistematicamente estimuladas e ampliadas de acordo com o desenvolvimento do aluno DV, de forma que os estímulos ambientais sejam significativos.

No contexto do ensino de ciências para alunos DV, um fator fundamental a ser desvendado refere-se ao conhecimento de atitudes e ações docentes dentro das práticas educativas com esses alunos (OLIVEIRA, 2002). Para tal, é indispensável a discussão em 
torno da formação do professor de ciências em cursos de licenciatura. Assim o presente trabalho buscou destacar a importância de estratégias que possam contribuir para que licenciandos se aproximem da realidade de alunos DV.

No contexto do presente trabalho, buscamos responder a seguinte pergunta: metodologia de trabalho de campo pode ser útil na sensibilização de licenciandos em Ciências Biológicas para o ensino inclusivo de alunos cegos?

\section{MATERIAIS E MÉTODOS}

A pesquisa contou com a participação de: 32 licenciandos do curso de Ciências Biológicas (cursando entre $1^{\circ}$ e $2^{\circ}$ períodos) das Faculdades Integradas Maria Theresa, Instituição de Ensino Superior (IES) privada do município de Niterói, RJ, acompanhados pela coordenadora do curso à época, Dra. Cristina Bassani; quatro colaboradores cegos congênitos (com idades entre 18 e 22 anos), acompanhados pela Professora Garrolice Alvarenga, mãe de um dos cegos e, à época, mestranda do Curso de Mestrado Profissional em Diversidade e Inclusão (CMPDI) da Universidade Federal Fluminense (UFF). O projeto foi aprovado pelo Comitê de Ética em Pesquisa da UFF $\left(\mathrm{N}^{0}\right.$ 1.067.544). Todos os participantes foram devidamente informados sobre o conteúdo da pesquisa e assinaram Termo de Consentimento Livre e Esclarecido (TCLE), Termo de Cessão de Imagem e Termo de Cessão de Imagem para Menor (quando aplicável).

Trabalho de campo foi realizado na praia de Boa Viagem, na cidade de Niterói, RJ, quando o primeiro autor do presente trabalho, biólogo, professor e, à época, realizou mergulhos para coleta de seres marinhos, visando ao estudo e ao reconhecimento dos organismos coletados durante atividade de natureza inclusiva.

Foram coletados_seres vivos pertencentes à fauna local e os acondicionou por tempo limitado em tanques especiais, para que os participantes da atividade pudessem tocá-los e observá-los.

Todos os seres marinhos foram devidamente acondicionados durante a manipulação e, ao final da atividade, devolvidos ao ambiente original sem que sofressem qualquer tipo de dano ou injúria e em respeito ao ecossistema em questão.

Atividades de campo envolvendo colaboradores cegos oportunizaram a licenciandos em Ciências Biológicas vivenciar metodologia de ensino inclusivo que privilegia o conjunto dos sentidos e a troca de experiências. Optamos por realizar trabalho de campo em biologia marinha, com realização de mergulho para coleta de organismos marinhos, por conta da ampla experiência do aluno nesta área. Entendemos, contudo, que a coleta de organismos marinhos para estudo não necessariamente é uma tarefa simples de ser conduzida por qualquer professor com seus alunos. 
A título de exemplos de objetos passíveis de serem estudados em trabalho de campo em biologia marinha, apresentamos as seguintes alternativas: areia, pedras, conchas, flora, vento, entre outras. Cabe ressaltar que nossa proposta de metodologia de ensino pode (e deve) também ser aplicada a trabalhos de campo que se proponham a explorar outros ecossistemas ou ainda outros ambientes externos. A metodologia de ensino, proposta neste trabalho, baseia-se em aproximar licenciandos de aspectos da realidade de pessoas com deficiências, para permitir reflexões sobre concepções prévias e, idealmente, impactar positivamente a formação docente para a prática inclusiva.

Os participantes foram instruídos e convidados a manipular organismos marinhos coletados, devidamente acomodados em tanques improvisados com água do mar. Licenciandos foram convidados a fechar os olhos e, através dos outros sentidos, incluindo o tato, a audição e o olfato, explorar as características dos organismos, tais como forma, tamanho, textura, entre outros.

Em seguida, ainda de olhos fechados, os licenciandos foram orientados a construir com massa de modelar um modelo tridimensional dos organismos observados. Os colaboradores cegos também foram convidados a manipular os organismos marinhos, de forma a realizar leitura tátil, sob observação dos licenciandos. Então, os cegos foram orientados a descrever as características desses organismos para os licenciandos que novamente fecharam os olhos, e, em seguida, passaram a confeccionar um segundo modelo que contemplasse as características descritas pelos cegos.

Após as atividades de campo, foi realizada uma roda de discussão que buscou sistematizar e avaliar criticamente as experiências vivenciadas e o conhecimento adquirido pela prática de ensino inclusivo.

Dois questionários foram aplicados aos 32 licenciandos que participaram da pesquisa antes (pré-teste) e após (pós-teste) a realização das atividades de campo, com o objetivo de coletar dados para se conhecer a concepção dos alunos sobre práticas inclusivas, em geral, e sobre a metodologia de ensino inclusiva por eles vivenciada, em particular.

O questionário inicial (pré-teste) buscou investigar se os licenciandos já haviam sido apresentados durante sua formação acadêmica ao desafio da inclusão no ensino, qual a importância esses davam para o tema e como imaginavam enfrentar esse desafio profissionalmente como professor.

O questionário apresentado após a realização das atividades (pós-teste) buscou investigar a validade da experiência vivenciada pelos licenciandos em relação aos seguintes aspectos: aplicação de metodologia similar para o enfrentamento da inclusão no ensino; viabilidade de reprodução e, ou modificação da metodologia para atender a outras áreas do 
ensino; relevância das atividades de campo para o ensino da disciplina; impacto da experiência para dilatar a utilização dos sentidos perceptivos no processo de sua própria aprendizagem; dificuldades encontradas para realização de qualquer uma das atividades; possível aplicação de atividades similares com alunos cegos.

Os questionários do pré-teste e do pós-teste apresentaram seis perguntas que se repetiram antes e depois da realização da metodologia de ensino inclusivo realizada durante a atividade de campo, com opções de respostas fechadas "sim" e "não", complementadas por respostas abertas. Essas perguntas incluíram questões gerais para avaliação do potencial de atividades de campo extraclasse no enfrentamento do desafio da inclusão no ensino. Adicionalmente, o questionário do pós-teste contou ainda com uma pergunta aberta exclusiva, que visou avaliar diretamente a metodologia de ensino inclusivo junto aos licenciandos entrevistados. Foram avaliadas tanto as atividades por eles vivenciadas durante a participação do trabalho de campo, como a possível contribuição da metodologia propriamente dita para a apreensão de novos conceitos visando à inclusão de alunos cegos no ensino.

A metodologia de análise de conteúdo proposta por Bardin (1977) foi aplicada para análise de categorias identificadas nas respostas abertas dos questionários. Para tal, inicialmente, buscou-se identificar os elementos que se agrupam por semelhança de sentido, de forma a inventariá-los para, depois, distribuí-los no conjunto de respostas obtidas, de forma a classificá-los. Assim, foi possível ressaltar de forma qualitativa os elementos indicadores que se destacavam como "núcleos de sentido" em "discursos" diversificados.

\section{RESULTADOS E DISCUSSÃO}

O presente trabalho desenvolveu, aplicou e avaliou metodologia de ensino inclusivo durante trabalho de campo em biologia marinha, o qual buscou integrar licenciandos de Ciências Biológicas e colaboradores cegos. Objetivou-se, dessa forma, sensibilizar os videntes, no caso potenciais futuros professores, a vivenciar situações em que passariam a explorar outros sentidos, e familiarizá-los com a experiência de não poder utilizar a visão nas atividades realizadas. Objetivou-se ainda que os licenciandos participantes percebessem a importância de desenvolvimento de metodologias que promovam o ensino inclusivo. Neste sentido, entendemos que atuamos para contribuir para a problematização dos desafios da inclusão durante o processo de formação docente.

A realização de trabalho de campo é valorizada no ensino de ciências como uma estratégia pedagógica, investigativa e interdisciplinar, conduzida em uma situação não-formal e extramuros escolares, capaz de ampliar a visão de homem, de natureza e de ambiente por seus participantes (JACOBUCCI, 2008). O trabalho de campo favorece a relação entre aspectos emocionais e a motivação dos alunos no contexto educativo. 
Em relação ao ensino inclusivo, podemos inferir que a estratégia de uso de trabalho de campo pode ainda aumentar o potencial dos benefícios provenientes de sua aplicação.

O trabalho de campo realizado, no presente trabalho, em uma praia urbana, em dia com clima aprazível, possibilitou um momento de interação prazerosa entre os participantes, cujos resultados, que serão aqui apresentados e discutidos, revelam a eficácia da metodologia sugerida para promoção na prática da educação inclusiva.

O início da atividade de campo que contou com a participação de 32 licenciandos em Ciências Biológicas e quatro colaboradores cegos se deu através de uma dinâmica de grupo conhecida como "Sinal de Trânsito". Essa dinâmica objetivou descontrair todos os participantes, videntes e cegos. A dinâmica consistiu em separar as pessoas em pares, um à frente e o outro atrás, o de trás com as mãos nos ombros do da frente, e o da frente com os olhos vendados (Fig. 1). Em seguida, os pares foram instruídos a caminhar pela areia da praia, sendo que o aluno posicionado atrás guiaria o aluno da frente através de toques nos ombros, respeitando-se os seguintes códigos: um toque com as duas mãos nos dois ombros ao mesmo tempo - iniciar o caminhar; um toque com a mão direita no ombro direito - virar à direita; um toque com a mão esquerda no ombro esquerdo - virar à esquerda; dois toques nos dois ombros ao mesmo tempo - parar. Os pares foram então orientados a trocar de posição, repetindo-se a dinâmica, sendo que o que ora fora guiado passou a guiar e o que ora guiara passou a ser guiado, de forma que todos experimentassem a sensação de não enxergar e depender de alguém para guiá-lo no seu caminhar (Fig. 1).

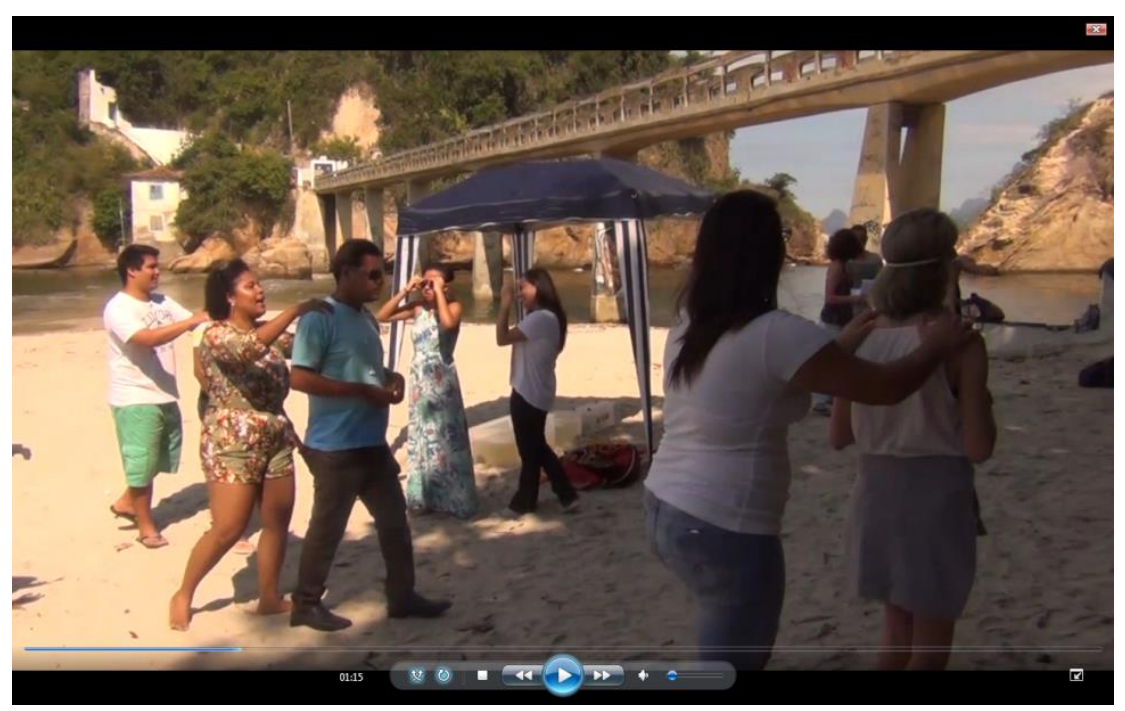

Figura 1: Realização da dinâmica "Sinal de Trânsito", incluindo participantes cegos e videntes. Fonte:Arquivo pessoal.

Cabe lembrar que a dinâmica realizada não representa a realidade da condução da pessoa cega, e não deve ser entendida como a maneira correta de conduzi-la. O correto é sempre perguntar à pessoa cega qual a melhor maneira para conduzi-la. Em momento algum, 
as atividades realizadas no presente trabalho tiveram a pretensão de equiparar a situação vivenciada pelos licenciandos videntes, ao terem seus olhos vendados, a situações reais vividas pelos cegos.

A dinâmica "Sinal de trânsito" ajudou a estabelecer um ambiente estimulador e descontraído. O objetivo foi criar as condições favoráveis para o processo ensinoaprendizagem, no que diz respeito ao desejo de aprender, à curiosidade, às motivações, às necessidades gerais de cuidados, à proteção, ao afeto, aos limites, ao convívio e à recreação (SÁ et al., 2007).

Em momento subsequente de condução das atividades de campo, equipamentos e materiais utilizados para mergulho e coleta de animais marinhos foram apresentados a todos os participantes, sendo que aos colaboradores cegos foi dada a oportunidade de manipulá-los para reconhecimento de forma e textura (Fig. 2). Foram apresentados, dentre outros, os seguintes materiais: roupa de neoprene de $5 \mathrm{~mm}$, nadadeiras de borracha (pés-de-pato), máscara de silicone com snorkel (canudo respirador).



Figura 2: Colaboradores cegos manipulando equipamento de mergulho. Fonte:Arquivo pessoal.

Em relação às atividades de estudo e reconhecimento dos organismos marinhos, os participantes foram separados em quatro grupos organizados em filas posicionadas à frente de cada um dos quatro tanques dispostos na areia da praia onde se encontravam imersos ouriçosdo-mar. Licenciandos e cegos foram, então, orientados de como deveriam manipular os animais, mantendo-se as mãos imersas na água do tanque, um de cada vez. Importante ressaltar que foram respeitadas todas as recomendações de forma a minimizar estresse dos animais durante manipulação, como, por exemplo, revezamento de animais por tanque, entre outros cuidados.

Os licenciandos foram inicialmente convidados a fechar os olhos e, através dos sentidos 
de tato, audição e olfato, explorar as características dos organismos, tais como forma, tamanho, textura, entre outras (Fig. 3).

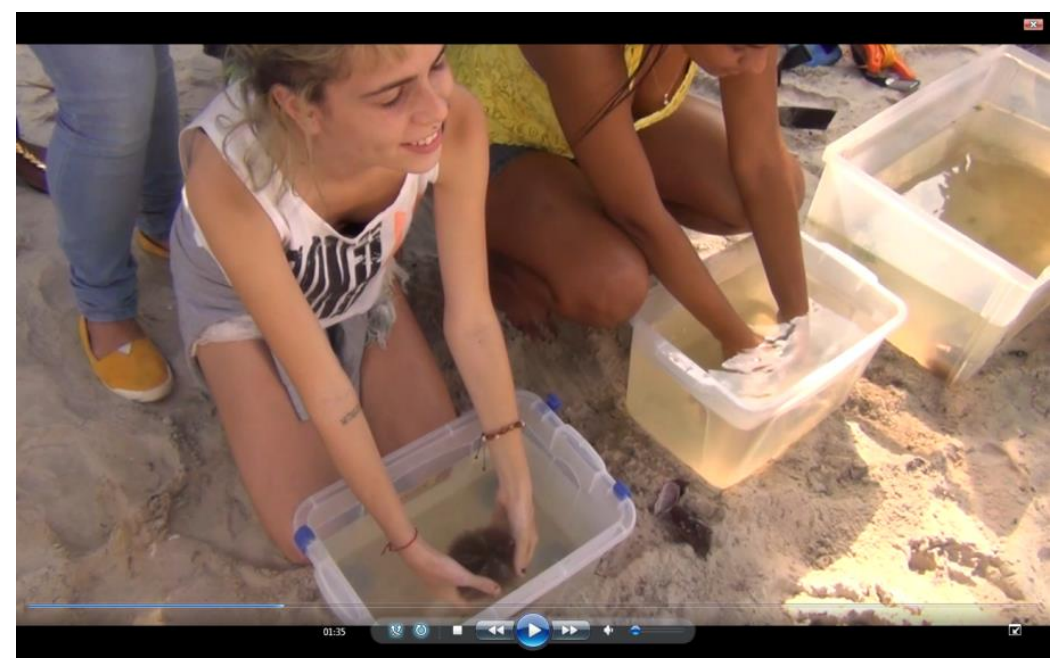

Figura 3: Manipulação dos seres marinhos por licenciandos videntes. Fonte: Arquivo pessoal.

A cada grupo de alunos videntes foi solicitado explorar com mais detalhes os organismos selecionados, de forma que, em momento posterior, foi pedido a eles, ainda com os olhos permanentemente fechados, que os reproduzissem através da construção de um modelo tridimensional utilizando-se massa de modelar (Fig. 4).

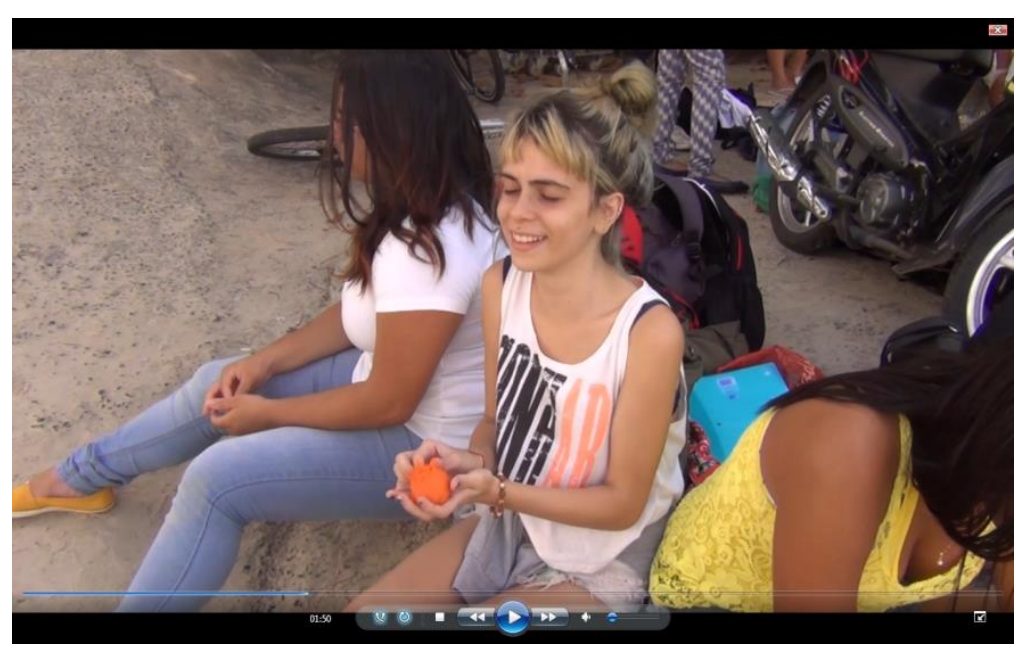

Figura 4: Construção de modelos tridimensionais dos seres marinhos utilizando massa de modelar

Após os licenciandos, os colaboradores cegos também fizeram a leitura tátil dos seres marinhos coletados (Fig. 5), um de cada vez. Eles foram então orientados a descrevê-los com detalhes para os licenciandos, os quais, neste momento, estavam com seus olhos abertos, de forma a observar como os cegos faziam para explorar objetos através do tato. Em um momento seguinte, novamente os licenciandos foram orientados a fechar os olhos e, a partir da descrição oral feita pelos colaboradores cegos dos organismos manipulados, confeccionar 
novos modelos tridimensionais. Esses modelos produzidos são apresentados na Figura 6.

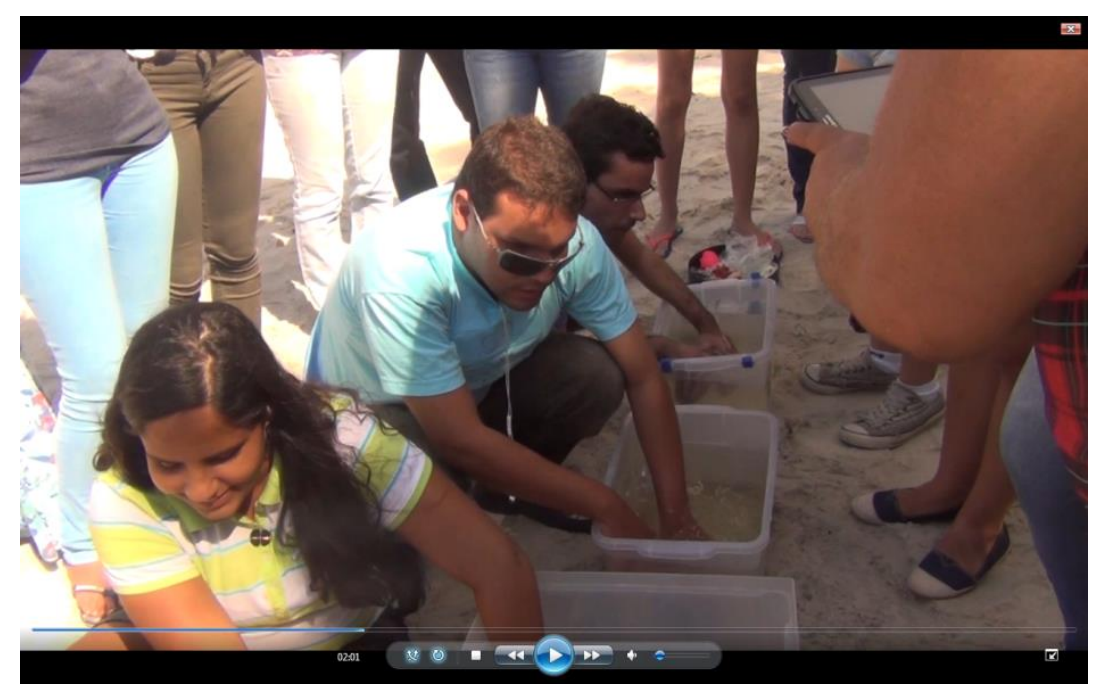

Figura 5: Leitura tátil pelos colaboradores cegos dos seres marinhos coletados.Fonte: Arquivo pessoal

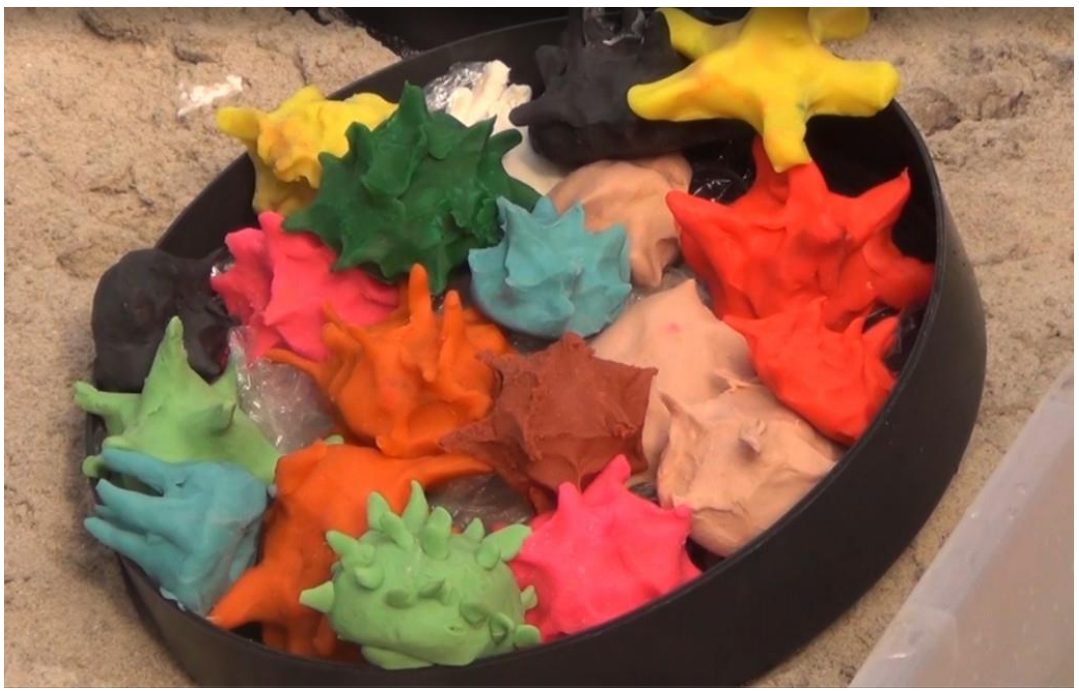

Figura 6: Modelos tridimensionais confeccionados em massa de modelar pelos licenciandos de olhos vendados, a partir da própria leitura tátil ou da descrição feita pelos cegos. Fonte: arquivo pessoal.

Uma rodada de discussão (Fig. 7) foi feita após manipulação dos organismos marinhos por todos os participantes e confecção dos dois modelos tridimensionais pelos videntes (uma orientada por leitura tátil; outra orientada pela descrição feita pelos cegos). O grupo foi convidado a expressar oralmente suas percepções sobre as diferenças identificadas a partir da experiência vivenciada de leitura tátil dos ouriços-do-mar. A discussão foi conduzida, particularmente, para oportunizar aos videntes compreender como os cegos são capazes de identificar com maior precisão detalhes a partir da leitura tátil. Portanto, os videntes foram introduzidos às especificidades e habilidades da percepção do ambiente por pessoas cegas, bem como à maneira com que essas pessoas são capazes de discernir formas, temperatura, 
textura, volume, densidade, cores, entre outras possibilidades. Foi possível compartilhar e comparar informações referentes às características propriamente ditas dos organismos manipulados, resultante da leitura tátil feita por videntes e cegos. Também foi possível comparar e avaliar criticamente os modelos desenvolvidos pelos videntes antes e depois das descrições feitas pelos cegos. Os licenciandos perceberam que os modelos confeccionados a partir da descrição dos cegos tenderam a apresentar mais detalhes, exatamente porque os cegos foram capazes de identificar características morfológicas e gerais dos ouriços-do-mar com maior precisão e detalhes que os videntes.

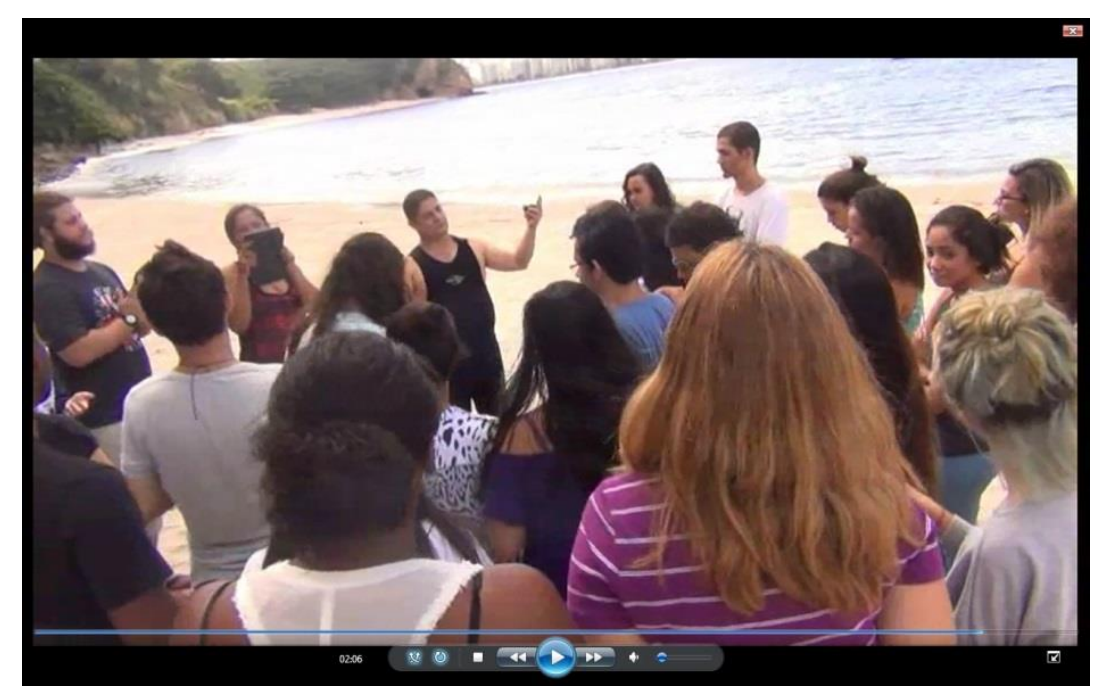

Figura 7: Roda de discussão com os licenciandos videntes e os colaboradores cegos. Fonte: Arquivo pessoal.

Após a aplicação do questionário em relação à pergunta "Você sabe o que é inclusão e diversidade?", os resultados apontaram que, dentre os 32 licenciandos entrevistados, 25 (78 \%) e 31 (97\%) responderam que sim, no pré-teste e no pós-teste, respectivamente. Ou seja, a metodologia aplicada durante o trabalho de campo, em termos quantitativos, contribuiu para de alguma forma mudar a percepção de seis alunos sobre inclusão e diversidade. Vale ressaltar que um dos entrevistados continuou assumindo no pós-teste que não havia compreendido estes conceitos.

Do ponto de vista qualitativo, observam-se mudanças nos perfis de respostas abertas dos entrevistados. Categorias que envolvem ações para conceituar inclusão, tais como "integrar, juntar, inserir, viabilizar, tornar acessível" aparecem com frequência similar em 43 falas, dentre as 57 falas analisadas e agrupadas por sentido, antes e após a vivência da metodologia de ensino inclusivo pelos licenciandos. Isso sugere que, no total, aproximadamente $75 \%$ dos licenciandos associam inclusão à ideia de que é preciso aproximar pessoas com características diferentes, umas das outras, bem como integrá-las ao meio, eliminando-se diferenças, preconceitos e limitações. Interessante identificar que, para 
pelo menos dois licenciandos, o conceito de inclusão foi apresentado pelo seu oposto, que é exatamente a exclusão.

Nesse caso, podemos inferir que, para eles, incluir significa contrapor a exclusão (incluir seria não excluir); ou seja, ainda que percebam a exclusão de indivíduos na sociedade, eles não conseguem expressar como se daria a inclusão.

O mais interessante, entretanto, foi perceber que, somente após a vivência da metodologia aplicada no presente trabalho, a qual exatamente buscou aproximar pessoas cegas e videntes, alguns licenciandos passaram a utilizar em suas falas termos como “direitos, oportunidades, iguais" para conceituar inclusão.

Segundo Stainback e Stainback (1999), o primeiro passo e, talvez o principal, para se alcançar uma escola inclusiva de qualidade é estabelecer os princípios democráticos e igualitários da inclusão, da inserção e da provisão de uma educação de qualidade para todos os alunos.

Ao serem questionados se já haviam participado anteriormente de alguma prática inclusiva, no pré-teste, somente quatro entrevistados (12\%) declararam que sim, sendo que no pós-teste, após participação da atividade de campo, 26 entrevistados (80 \%) passaram a declarar que sim. No pré-teste, os quatro (12\%) licenciandos que declararam "sim" apontaram quais seriam essas práticas, a saber: capoeira com deficientes físicos e visuais; evento de recepção na universidade de um aluno surdo; inclusão digital em comunidade; defesa de dissertação de mestrado com intérprete de Libras. Chama atenção o fato de que 88 $\%$ das pessoas do grupo investigado no pré-teste, até então, nunca tinham participado de nenhuma prática inclusiva, o que reflete um percentual bastante significativo. No pós-teste, a quase totalidade dos licenciandos apontou como prática inclusiva a participação no trabalho de campo em conjunto com os cegos, Por outro lado, chama atenção também o fato de que seis $(20 \%)$ licenciandos continuaram assumindo no pós-teste que nunca haviam participado de nenhuma prática inclusiva. Este último dado revela que, mesmo tendo acabado de participar de uma prática inclusiva, alguns indivíduos não conseguiram apreendê-la como tal, o que nos faz acreditar que ações diversificadas e plurais são necessárias para sensibilizar pessoas para a realidade da inclusão.

Segundo Castanho e Freitas (2006), o movimento de incluir é uma forma de tornar a sociedade mais democrática, sendo papel de todos os cidadãos transformar as instituições de ensino em espaços legítimos de inclusão. Portanto, a inclusão é um processo complexo inserido na organização da educação que necessita de ações transformadoras e de perspectivas realistas frente à importância de garantir a todos o direito à educação. 
Quando perguntados se um aluno cego poderia ter aula de biologia marinha como os alunos videntes, $30(94 \%)$ e $31(97 \%)$ entrevistados responderam afirmativamente à resposta, no pré-teste e no pós-teste, respectivamente. O alto percentual de respostas afirmativas demostra que os entrevistados, em sua grande maioria, entendem que a deficiência visual não significa necessariamente uma limitação de acesso a determinado tipo de atividade prática extraclasse no ensino. Interessante ressaltar que a pergunta aberta solicitava justificativa somente em caso de uma reposta negativa; entretanto, ainda assim, nove $(29 \%)$ entrevistados apontaram suas impressões sobre possibilidades dos cegos e necessidades de adaptações pra atendê-los no ensino. Da análise das falas dos entrevistados, podemos destacar as seguintes categorias de sentido que apareceram com maior frequência: (i) os cegos podem aprender como qualquer pessoa, mas são necessárias adaptações para atender às suas necessidades; (ii) a aprendizagem do cego envolve exploração de outros sentidos como tato e audição; (iii) os cegos precisam ter a mesma experiência que os videntes.

A limitação da visão, por si só, não é impedimento para apreensão do mundo pela pessoa cega, pois essa não contempla a possibilidade total da apropriação da linguagem (LIRA \& SCHLINDWEIN, 2008). Segundo Freitas (2006), a limitação da visão nos cegos é especialmente compensada pelo tato, o qual se constitui em um meio extraordinário de comunicação e apreensaão do mundo, que se encontra presente por toda a pele. Sensores táteis e cinestésicos favorecem a percepção e o processamento de dor, posturas, movimentos, temperaturas, pressão, dentre outros, fornecendo profundidade associativa, integrativa e intencional.

Ao responder à pergunta sobre se existem limitações para os alunos com deficiência visual, $19(60 \%)$ dos entrevistados no pré-teste afirmaram que sim. Nessa pergunta, foi solicitado aos licenciandos que responderam "sim", que justificassem suas respostas. As principais categorias de sentido identificadas a partir da análise das falas do licenciandos dizem respeito às limitações que podem ser superadas com a presença de acompanhantes especializados em atender às necessidades específicas dos cegos.

Ao serem questionados se existem atividades de campo que permitam a pessoas videntes e cegas participar em condições de igualdade, 28 (88 \%) e $32(100 \%)$ entrevistados responderam que sim, no pré-teste e no pós-teste, respectivamente. Observamos, portanto, que, após participarem das atividades de campo, aparentemente todos os alunos foram sensibilizados para a relevância e aplicabilidade de uma metodologia inclusiva de ensino capaz de integrar e aproximar pessoas, superando possíveis diferenças e limitações. 
Ao final da realização das atividades de trabalho de campo em biologia marinha, no questionário pós-teste, os licenciandos puderam avaliar através de pergunta aberta a metodologia de ensino por eles recém-vivenciada e a sua contribuição para subsidiar a formação de novos conceitos para a educação inclusiva de alunos cegos. Dentre os 32 entrevistados, 29 (90\%) licenciandos responderam à pergunta aberta, sendo que todos avaliaram positivamente as atividades realizadas. Foram identificados os seguintes adjetivos mais frequentes nas falas dos licenciandos: ótimo (4), excelente (5), importantíssima (3), boa (2), interessante (2), maravilhosa (2).

Do ponto de vista qualitativo, os dados obtidos nos permitem inferir que, para a maioria dos licenciandos, a vivência da metodologia de ensino compartilhada por colaboradores cegos durante trabalho de campo em uma praia urbana contribuiu para a promoção da inclusão, objetivo principal do presente trabalho. Fundamentalmente, identificam-se percepções novas ou renovadas dos licenciandos sobre questões relacionadas ao olhar de videntes sobre pessoas com deficiência visual e seus potenciais para além das diferenças. A avaliação mostrou a viabilidade da aplicação da metodologia de ensino inclusivo proposta neste trabalho quanto ao seu potencial para: (i) compreensão de particularidades do processo de ensino-aprendizagem de cegos; (ii) desconstrução de preconceitos (conceitos prévios); (iii) promoção da inclusão na prática; (iv) sedimentação de conceitos de inclusão no processo de formação de docentes em cursos de licenciatura de Ciências Biológicas.

\section{CONCLUSÃO}

Considerando o conjunto das atividades realizadas, concluímos que o simples fato de aproximar videntes e cegos durante trabalho de campo realizado ao ar livre, em condições lúdicas de aprendizagem, possibilitou que experiências e conhecimentos pudessem ser compartilhados, independentemente das diferenças entre as pessoas. Dizendo de outra forma, no contexto do ensino inclusivo, práticas que aproximam videntes da realidade dos cegos podem contribuir para que ambos percebam que aprendizagem é resultante de formas diversificadas e compartilhadas de leitura e apreensão do mundo ao redor e que essa nunca se limita a um único sentido. Mais ainda, práticas de natureza inclusiva, fundamentalmente, podem contribuir para facilitar a interação entre as pessoas sem que as diferenças sejam valorizadas e imponham limitações ao desenvolvimento humano. A fala de um dos licenciandos participantes do presente trabalho, a seguir transcrita, ilustra a força de tal afirmação: "Estou envergonhado! Cheguei aqui e me deparei com quatro cegos e, quando soube que eles iriam participar das actividades, disse logo: impossível, eles não enxergam! Mas, após as actividades, quando descreveram em detalhes tudo o que eu não consegui perceber... Peço desculpas a cada um aqui presente pela minha prepotência!’. 
Concluímos, adicionalmente, que a metodologia desenvolvida no presente trabalho, tem potencial como prática alternativa de ensino que privilegia o conjunto dos sentidos e a troca de experiências para a promoção da inclusão de pessoas cegas. Particularmente, tal potencial se expande na medida em que a metodologia desenvolvida se aplica à formação de licenciandos em Ciências Biológicas, futuros professores que, certamente, serão convocados em suas vidas profissionais a lidar com o desafio permanente da inclusão no ensino.

\section{REFERÊNCIAS BIBLIOGRÁFICAS}

ALARCÃO, I. (1996). Formação reflexiva de professores: estratégia de supervisão. Porto: Porto Editora.

BARDIN, L. (1977). Análise de Conteúdo. Lisboa: Persona.

BUENO, J. G. S. (1999). Crianças com Necessidades Educativas Especiais, Política Educacional e a Formação de Professores: generalistas ou especialistas? Revista Brasileira de Educação Especial, Piracicaba, v.3, n.5, p.7-25.

CASTANHO, D.M.; FREITAS, S. N (2006). Inclusão e prática docente no ensino superior. Revista Educação Especial, n. 27, p. 93-99.

FERREIRA, W. B. (2006). Inclusão x exclusão no Brasil: reflexões sobre a formação docente dez anos após Salamanca. In: Inclusão e educação: Doze olhares sobre a educação inclusiva. Davi Rodrigues (org.). São Paulo: Summus,.

FREITAS, S. N. (2006). A formação de professores da educação inclusiva: construindo a base de todo o processo, in: David Rodrigues (org.), Inclusão e Educação: doze olhares sobre a educação inclusiva. São Paulo: Summus.

JACOBUCCI, D. F. C. (2008). Contribuições dos espaços não-formais de educação para a formação da cultura científica. Revista Em extensão, 7, 55-66.

LAYTON, C.A.; LOCK, R.H. (2001). Determining learning disabilities in students with low vision. Journal of Visual Impairment \& Blindness, May, 288-298.

LEDERMAN, S.J.; KLATZKY, R. L. (1987). Hand movements: a window into hapic object recognition. Cognitive Psycology: General, 114: 342-368.

LIRA, M. C. F.; SHILINDWEIN, L. M. (2008). A pessoa cega e a inclusão: um olhar a partir da psicologia histórico-cultural. Caderno Cedes, 28(75), 171-190. 
MASINI, E. A.S. (2007). As especificidades do perceber: diretrizes para o educador de pessoas com deficiência visual. In: A pessoa com deficiência visual: um livro para educadores. Primeira edição. Vetor.

OLIVEIRA, A. A. S. (2002). Representações sociais sobre Educação Especial e deficiência: o ponto de vista de alunos deficientes e profissionais especializados. Tese (Doutoramento em Educação) - Faculdade de Filosofia e Ciências, Universidade Estadual Paulista, Marília.

SÁ, E. D.; CAMPOS, I. M.; SILVA, M. B. M. (2007). Atendimento Educacional Especializado para Deficiência Visual, SEESP, SEED, MEC: Brasília Distrito Federal, p.1357.

STAINBACK, S.; STAINBACK, W. (1999). Inclusão: um guia para educadores. ARTMED Editora.

THOMAS, G.; WALKER, D.; WEBB, J. (1998). The Making of the Inclusive School. London: Routledge. 